\title{
CULTURAL JUSTICE, BASIC INCOME AND THE CAPABILITY APPROACH
}

\author{
TORU YAMAMORI ${ }^{1}$ \\ ${ }^{1}$ Doshisha University, Faculty of Economics, 601 Genbu-cho Kamigyo, Kyoto 602-8580, Japan. ORCID: \\ 0000-0003-3533-1064, Email: toruyamamori@gmail.com
}

\begin{abstract}
In this paper, we elaborate a theory of an evolutionary political economy capable of accommodating the issue of cultural justice by taking seriously the redistribution-recognition dilemma, a normative analysis of which has been put forth by Nancy Fraser. While accepting Fraser's articulation of the dilemma, we resist her concluding that Sen's capability approach is insensitive to cultural justice or the recognition of difference. There is no automatic guarantee, yet an intermediate theory of recognition or cultural justice could in theory be brought to bear on what is, after all, 'a framework'. We argue that Fraser's analysis is well suited to be such an intermediate theory, and propose a theoretical device for an evolutional perspective on redistribution and recognition. We concentrate on identifying the stage of the market process at which policy intervenes to remedy redistribution, and the stage of the communication process at which policy intervenes to remedy recognition. Interventions at the entrance stages of both processes are relatively effective and one possibility for such an intervention is to propose Basic Income, which would make it not inconsistent with the capability approach, even though this approach neither directly suggests such a policy not excludes others.
\end{abstract}

KEYWORDS: Amartya Sen, Basic Income, Evolutionary political economy, Nancy Fraser, Recognition 


\section{INTRODUCTION}

$\mathrm{I}^{\mathrm{n}}$ $n$ this paper, I try to make an argument for the kinds of social policies that more effectively facilitate cultural justice. I limit this argument to normative deliberation, specifically to Nancy Fraser's and Amartya Sen's work.

I begin by giving the definitional outlines of cultural justice as the term has been used rather vaguely. I then go on to explore how normative theories have been thought to treat such cultural justice, relying primarily on Nancy Fraser's framework. I build on her insights regarding evolutional political economy, recognition and redistribution - the argument being that the Basic Income proposal is one of those social policies that facilitate recognition and the deconstruction of difference. I resist Fraser's critique of Sen, and show how Sen's work about identity is compatible with Fraser's (and my) framework.

\section{DEMAND FOR THE RECOGNITION OF CULTURAL IDENTITIES}

The term culture on its own is used to mean the customs and beliefs, the art, way of life and social organisation of a particular group - not exclusively construed as an ethnic or national group. In the literature on the development or theories of justice, however, culture is sometimes equated with ethnicity. ${ }^{1}$ Whenever the term "multiculturalism" is used, for example, that tendency becomes more apparent. Although this use of the term culture may have many merits, in this paper, I choose to broaden the definitional scope: in my usage, a particular group could certainly be an ethnic group, but it could just as well be a group formed along other demarcations (gender, disability, sexuality and so on).

I am guided in this use of the term by several academic traditions. First, recent discussions on culture in philosophy have brought the term "recognition" to the fore. This term, which I shall shortly explain, connotes broader usage. Second, social theory after the linguistic turn has focused on "social construction". This "constructionist" view, open to the broader definition of culture ${ }^{2}$ contrasts with the "essentialist" view of culture held by those who consider culture to be solid, given and non-problematic. Third, cultural studies have changed the tradition of the academic left that exclusively focuses on material substructure, and have focused on the superstructure instead an influence palpably felt in the rise of subaltern studies and post-colonialist literatures, where the term "cultural" is meant again in a broader sense $\mathrm{e}^{3}$.

Let us return to the term 'recognition'. The revival of this Hegelian term in modern political philosophy owes much to Axel Honneth, Charles Taylor, and Nancy Fraser. Honneth's The Struggle for Recognition (Honneth 1992) reconceptualises the term in order to articulate the struggle for emancipation of disadvantaged groups (Honneth 2000).

While the groups mentioned by Honneth are proletarian at large, Taylor connects

\footnotetext{
${ }^{1}$ For example, Mani(2002), Kelly(2002). See Woolcock, Rao and Alkire(2002) for a critical survey of development economics.

${ }^{2}$ See Butler (1990) for an example of this analysis concerning gender identity.

${ }^{3}$ Stuart Hall is a representative example of the authors of the studies I mention here.
} 
the term directly to the struggle over identity and difference, or to multiculturalism.

A number of strands in contemporary politics turn on the need, sometimes the demand, for recognition... [T] he demand comes to the fore in a number of ways in today's politics, on behalf of minority or "subaltern" groups, in some forms of feminism and in what is today called the politics of multiculturalism (Taylor 1992: 25).

Fraser clarifies this concept by contrasting it to redistribution, both in philosophy and in social science. Philosophically, the theory of recognition is supposed to rectify the shortcoming that the theory of redistribution (i.e. theories of distributive justice) cannot take recognition seriously, in Fraser's framework. Theorists of distributive justice would be, for example, Karl Marx, John Ralwls, Ronald Dworkin, and Amartya Sen. Fraser insists that they cannot treat cultural justice properly. The dispute over whether her conclusion is plausible or not is not one I would wish to enter here. However, I shall return to this issue in Sen's case in a later section. In social science, traditionally, social struggles are understood in terms of struggle against economic inequality or exploitation. It is still an effective proposition, but not one that can cover properly current social struggles, which are struggles also against cultural misrecognition (Fraser 1997).

\section{THE REDISTRIBUTION-RECOGNITION DILEMMA AND BEYOND}

Fraser's claim, however, is not that the theory of recognition should replace the theory of redistribution in philosophy, nor that the politics of recognition should replace the politics of redistribution in social science (or in the real world). Fraser acknowledges how recognition and redistribution are deeply “intertwined" (Fraser 1997: 15). Her purposeful distinction between recognition and redistribution is meant to identify and analyse a dilemma experienced in current social struggles, while also pointing to ways in which we could go beyond this dilemma.

The name she gives to the dilemma is "the redistribution-recognition dilemma" (Fraser 1997: 13) and it happens as follows. The simultaneous pursuit of redistribution and recognition can create a contradictory situation. To win equal distribution of resources, oppressed and disadvantaged minority groups are often forced to claim that they are "the same" as the majority. For example, in order to obtain equal qualification for entrance examinations to universities in Japan, high schools privately run by ethnic minority groups must insist that their educational system is the same as that of public schools strictly adhering to the guidelines of the ministry of Education, Culture, and Science. Likewise, to obtain equal opportunities for work, women have to claim they are as capable of working as men. This kind of situation will contradict the demand for the recognition of difference.

Even when recognition of difference is pursued with view to equal redistribution, there will be cases where the majority remains the same, while the minority is unilaterally rated as inferior. This type of recognition, first, may end up justifying the inequality of distribution. Second, even if redistribution actually takes place, it will 
come with stigma attached. This form of recognition runs the risk of giving relief as an outcome, but without questioning the social cause of creating a disadvantaged minority. In this case, the politics of recognition reproduces and perpetuates the dominant norm that creates disadvantaged minorities in the first place. Such results are not what the claim of recognition set out to accomplish.

As far as issues of gender are concerned, the dilemma maps over onto the tension between "equality feminism" and "difference feminism." Similar dilemmas exist in all the problems that separate relatively marginalised and stigmatised minorities from the normalised or privileged majority, not only with respect to gender, but also with regard to other issues such as disability and sexuality.

Then, how could we avoid or go beyond such a dilemma? Fraser distinguishes transformative remedies from affirmative remedies and advocates the former in both redistribution and recognition. For redistribution, the affirmative remedy is represented by "the liberal welfare state", which does "surface reallocations of existing goods to existing groups; supports group differentiation; can generate misrecognition.” The alternative, transformative remedy for malredistribution is represented by "socialism", which can be a "deep restructuring of relations of production; blurs group differentiation; can help remedy some forms of misrecognition (Fraser 1997: 27).” For recognition, the affirmative remedy is represented by "mainstream multiculturalism", which does "surface reallocations of respect to existing identities of existing groups; supports group differentiations." Fraser's term for the alternative, transformative remedy for misrecognition is "deconstruction," which could be a "deep restructuring of relations of recognition; [destabalising] group differentiation (Fraser 1997: 27).” The distinction she makes with regard to recognition corresponds to the distinction between essentialism and constructionism in social theory and cultural studies.

\section{EVOLUTIONAL POLITICAL ECONOMY FOR RECOGNITION AND REDISTRIBUTION}

I tried to connect Fraser's proposal as summarised above in Evolutional Political Economy or Social Economics (Yamamori 2000). Allow me to explain it briefly here. Fraser's solution is to make the boundary fluid. It urges us to focus not on static outcomes, but on dynamic processes of redistribution and recognition. Figure 1 represents these dynamic processes.

My first proposition is to consider the "market" as the space of redistribution. Now, imagine the market as a game where goods are exchanged, as Neoclassical Economists think, though the real market is not so simple. We can locate three stages at which to intervene in the redistribution process: the entrance (opportunity), the game, and the exit (outcome). The usual intervention-justifying norm is that of "national minimum" or "social citizenship." It does not logically define where the intervention should occur, but existing interventions based on this norm tend to the exit stage. If this game (market) itself were sacred and absolute, it would be unjust to intervene in its processes at any stage. And indeed, libertarians like Robert Nozick might make such a contention (Nozick 1974). Characteristic of this game is that were some players to 
lose the game or be unable to enter it for lack of marketable goods or a labour force to sell, then they must not only drop out of the game but also must die. It is for this reason that Friedrich von Hayek justified minimum intervention at the exit in order to preclude a player's demise. Taking this game more seriously, however, it is unfair if the conditions of the players at the entrance are unequal, because the inequality at entrance would entail inequality at exit. Therefore, ensuring equality at the entrance is important. The norms of "equal opportunity" and the normative theories of Rawls and Sen embody this idea.

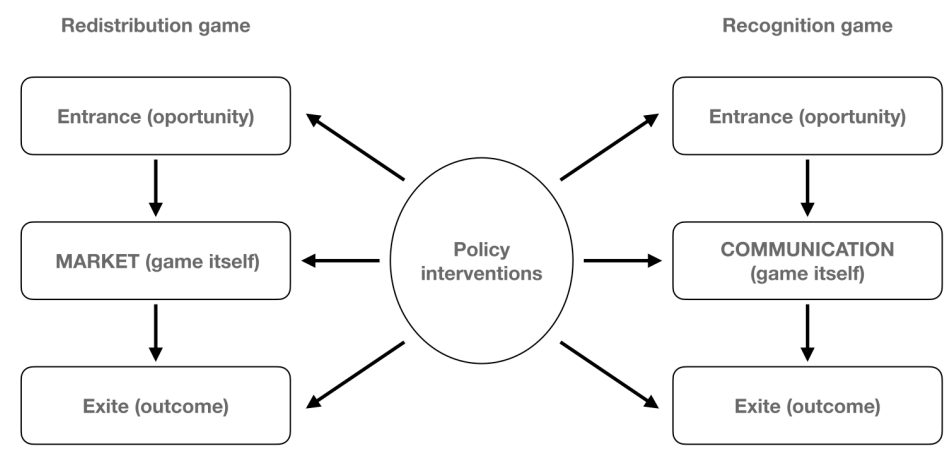

Figure 1. Three Stages of Redistribution and Recognition Source: Yamamori (2000: 238).

My second proposition is to examine "communication" as the space of recognition. Imagine "communication" as a game where identity is mutually recognised, following Jürgen Habermas (Habermas 1981), although real communication is not so simple. The influential normative arguments in justification of "recognition" are "multiculturalism," "difference feminism" and the theories of Taylor and Carol Gilligan (Taylor 1992; Gilligan 1981). In these essentialist arguments, the game is considered as given and unproblematic. The focus is on "recognition" only at the exit stage. These arguments share a common problem with the predominant paradigm of ignoring "recognition." They do not even think that the game exists, and hold in common a characteristic of not paying attention to the game. The identity at the exit, regrettably, is not always supportive and unproblematic, because usually the conditions at the entrance are unequal. Some players have more discursive resources, including the advantage of social norms, than others. Inequality at the entrance will have a considerable effect on inequality at the exit. "Constructionism", as noted above, acknowledges this factor.

In both redistribution and recognition, interventions at the exit tend to a fixity of the boundaries. Social assistance is an intervention at the exit of the market. In contrast to the policy of intervention at the entrance such as "Basic Income", which I will discuss in the next section, this social policy draws a line separating "independent" citizens from "dependent" welfare recipients, leading to a reinforcement of boundaries. Another example is affirmative action, a policy of intervention at both market entrance and communication exit. While this policy has a lot of positive effects on 
redistribution, it too, tends to fix boundaries in terms of recognition.

From what has been said above, I conclude that intervention at the entrance or in the game itself is indispensable in overcoming boundaries. This is not to deny the importance of intervening at the exit. The normative theories of Rawls and Sen justify intervention at the entrance, but do not intervene in the game itself. As we intervene in the market and communication games, we must realise that the game is neither a natural nor an unchangeable institution.

\section{BASIC INCOME}

In this section, I argue for Basic Income in line with Fraser's solution (described in Section 3) and in accordance with the Evolutionary Political Economy of Recognition and Redistribution (described in Section 4). Basic Income is an unconditional guaranteed income for all. Philippe van Parijs defines it as "an income paid by a government, at a uniform level and at regular intervals, to each adult member of society." It is paid "irrespective of whether the person is rich or poor, lives alone or with others, is willing to work or not." The membership referenced here extends to "not only citizens, but to all permanent residents (van Parijs 2001: 5). There are three reasons why Basic Income (BI) is called "basic". First, it is a basic platform which "[a]ny other income whether in cash or in kind, from working or saving, from the market or the state - can lawfully be added to (van Parijs 2001: 6)." Second, it helps to satisfy people's "basic needs." ${ }^{4}$ Third, it is an entitlement derived from "basic human rights."

How is BI assessed in terms of my argument in this paper? As regards the redistribution aspect, i.e. in the game of the market, BI is obviously an intervention at the entrance. The "socialism" which Fraser recommends as a transformative remedy is an intervention in the game itself. As I explained earlier, both interventions at the entrance and in the game itself (as compared to interventions at the exit) tend to help make the boundary fluid. So even though Fraser made no mention of it, BI is also one such alternative transformative remedy.

As regards the recognition aspect, I would like us to pay attention to several features of BI that distinguish it from the traditional welfare state system. First, BI would be paid, not only to citizens, but also to permanent residents. It would be paid irrespective of whether they are poor or rich, have the will to work or not. All of these would help blur the boundaries on a number of points (national identity, class identity, the identity of welfare dependency). Second, BI would be paid not on the basis

\footnotetext{
${ }^{4}$ See Baker(1992). Demand for Basic Income in the Claimants Union movement in the U.K. was based on this strong connection (Jordan 1973, Yamamori 2003a). However, I have to note that van Parijs explicitly denies this connection between Basic Income and basic needs (2001: 6). This denial is relevant to his justification of BI in terms of his Real Libertarianism (van Parijs 1995). While I have been strongly influenced by his works, and I think his justification is powerful and effective in the context of the dominance of Neo-Liberalism, I am not sure when he said BI is "a material foundation on which a life can firmly rest (2001: 5-6)," how far removed and unconnected to basic needs this level of "material foundation" could be.

${ }^{5}$ Robeyns (2000) calls attention to the fact that BI could be gender sensitive only in conjunction with other policy packages which facilitate gender equality.
} 
of households, but on an individual basis. This holds some potential for changing the (dis)balance of gender relations within households, although this is not automatically guaranteed. ${ }^{5}$ Third, in the strong version of BI (perhaps in the version of van Parijs), social policies intended to compensate for past discrimination against a particular group, such as affirmative action or positive discrimination, might diminish. While those social policies are a compensation both for a maldistribution and a misrecognition at the exit of the games, market and communication, BI is an intervention at the entrance of both games. Therefore, Basic Income is a good candidate that can go beyond the redistribution-recognition dilemma.

\section{SEN ON IDENTITY}

Let us go back to the question of whether Fraser's negative conclusion about distributive theories is justified or not. In the case of Sen, it is controversial, not only because "Sen treats a 'sense of self' as relevant to the capability to function (Fraser 1997: 33)," but also because his concept of capability itself is detached from emphasis on resources distribution, in contrast to Rawls" “social primary goods” or Dworkin's “resources”. Indeed, Ingrid Robeyns (2003) strongly argues against Fraser. While Robeyns admits that Fraser's intention to introduce recognition matters in the field of theory of justice, she criticises Fraser for oversimplifying theories of distributive justice, and for getting it wrong as far as Sen's approach is concerned. Robeyns also concludes that Fraser's suggestion for an alternative (not the transformative remedy that I mention in this paper, but Participatory Parity) is "included in the capability approach, whereas the capability approach also points to some normative considerations of (mis-)recognition (Robeyns 2003: 550).” I agree with Robeyns on the first claim; the validity of the second I will not discuss here, however, what I would like to bring forth is the clarity of her characterisation of the capability approach as "framework". She argues the capability approach is "an evaluative framework, not a fully specified theory.” (Robeyns 2001: 3) Therefore, it is "open" to diverse interpretations, so if we want further specifications of the approach, we need additional "explanatory theories (Robeyns 2004: 1)." I would like to argue that Fraser's theory (and my argument for evolutional political economy for recognition and redistribution) can be such an explanatory theory for when we want to make the capability approach difference-sensitive.

The capability approach could be difference-sensitive for several reasons. First, it shifts the informational basis from who (what person) possesses (goods) to what a person can do or be (capabilities) (Sen 1980, 1992). The focus moves to diversity derived from the different ways in which a person converts goods to capabilities. Second, contrary to utilitarianism, the capability approach is associated with disaggregated measure, not with sum-ranking (Sen 1982, 1992). It could zero in on the situation of minority groups. However, this sensitivity is only a possibility, so we need an explanatory theory. Furthermore, the capability approach itself does not suggest directly what kind of social policy would facilitate just recognition. So again - the need for an additional theory or explanation. But on what basis can we count Fraser's theory as one such? I would like to argue that Sen's work on need and identity points in a con- 
structionist direction ${ }^{5}$, and that is also the direction taken by Fraser.

Fraser's analytical distinction between redistribution and recognition could be rephrased as a distinction between need distribution and need interpretation (Fraser 1989). Sen's capability approach primarily concerns need distribution, but there are some aspects of need interpretation. He places emphasis on the necessity for self-evaluation (Sen 1987: 32) of capability and functionings. Self-evaluation is different from utility, and "self-evaluation is quintessentially an evaluative exercise, which none of the interpretations of utility in itself is. The issue of paternalism, when it does arise, must relate to the rejection of the person's self-evaluation (rather than of utility) (Sen 1987: 32)." In his capability approach, the extent to which one's self-evaluation of one's capability compromises prevailing perceptions of capability as social standards is by no means immediately apparent. It should, therefore, not be assumed that the debate over need-interpretation has thus far taken an entirely appropriate direction within the capability approach. Sen does, however, recognise that the process of need interpretation itself takes place within a rather separate dimension from the narrow focus on need-distribution. Outside of the context of the capability approach, Sen notes:

The totality of the human predicament would be an undiscriminating basis for the social analysis of needs. There are many things that we might have good reason to value if they were feasible, maybe even immortality; yet we do not see them as needs. Our conception of needs relates to our analysis of the nature of deprivations, and also to our understanding of what can be done about them. Political rights, including freedom of expression and discussion, are not only pivotal in inducing political responses to economic needs, they are also central to the conceptualization of economic needs themselves (Sen 1994: 36).

Sen has criticised the dichotomisation of need and freedom (e.g. political rights, democracy). The strength of this claim lies first of all in the fact that it identifies the importance of an often-overlooked relevance: the relevance of freedom to respond to need fulfilment. I would like to pay attention to the relevance of freedom to define needs, in the context of this paper. This freedom and political rights that Sen points to could be interpreted as a freedom or right to participation in the public sphere (and the game of communication - to use the terminology of Section 4). One could also say that this stance gives careful consideration to the concept of need as a social standard as well as respects the social construction of needs, thereby suggesting that need must take shape within processes of the public sphere. Furthermore, however, he asserts that the formalised rights and freedom to the public sphere have severe limitations. "It is important to acknowledge, however, the special difficulty of making a democracy take adequate notice of some types of deprivation, particularly the needs of minorities (Sen 1994: 36)."

Sen doesn't respond directly to this difficulty, but does appear to hint at one specific direction in his treatment of identity (Sen 1985, 1998, 2001). He is wary of consid-

\footnotetext{
${ }^{6}$ I already argued this elsewhere (Yamamori 2003b), so the following argument was there in a slightly different version.
} 
ering a single identity as a stable or solid entity. First, “[w]e all have many identities (Sen 1985: 348)." Second, identity is not discovered, but rather, it is chosen by reason (Sen 1998). Third, he distinguishes the "epistemic" use of identity from the "ethical" use of it, and only advocates the former (Sen 2001). In addition, the social norms that are the result of the social construction of need are not the primary point of theoretical departure. This approach to identity (summed up as "plural identity," "identity choice," "beyond identity" in Sen, 2001) overlaps with Fraser's and mine, although the terminology is different. In my terminology, Sen is not only aware of the recognition aspect, but is also aware that the consequence (exit) of the game of communication is sometimes negative and that we can resist it. This concern of Sen's becomes clear in the following statement: "[t]he prevailing perceptions of "normality" and "appropriateness" are quite central (Sen 1999: 116) " to some sort of question like gender inequality.

All of these arguments suggest a constructionist direction. I called this tendency in Sen "constructive universalism (Yamamori 2003b)". Although it might be epistemologically different from Fraser's "deconstructionist" approach, it could still enable us to connect these two theories to each other in order to evaluate social policies from a normative perspective.

\section{CONCLUDING REMARKS}

Allow me briefly summarise the discussion above, in a slightly different order. The capability approach developed by Sen can be sensitive to cultural justice or the recognition of difference. Being just a "framework", it could theoretically be associated with an intermediate theory of recognition or cultural justice, but at the same time, there is not automatic guarantee. I argue that Fraser's analysis is suitable for such an intermediate theory, and propose a theoretical device for an evolutional perspective of redistribution and recognition. The focus is on choosing the stage of the market process at which policy intervenes to remedy redistribution, and on choosing the stage of the communication process at which policy intervenes to remedy recognition. Interventions at the entrance stages of both processes are relatively effective and a Basic Income (BI) proposal is one possibility for such an intervention.

Thus we could conclude that the BI proposal is not inconsistent with the capability approach, even though this approach neither directly suggests such a policy not excludes other policies.

FUNDING: Work underlying parts of this paper was supported by a grant from the Japan Society for the Promotion for Science (13730043).

CONFLICT OF INTEREST: The author declares no conflict of interest.

ACKNOWLEDGEMENTS/POSTSCRIPT: This paper was presented at the 4th International Conference on the Capability Approach, 4-7, September 2004, Pavia, Italy. A slightly different version was delivered under the title 'Basic Income and Capability Approach: On Recognition and Deconstruction for 
Difference' at the 10th Basic Income European Network Congress, 19-20 September 2004, Barcelona, Spain. I was grateful for the warm reception and comments on both these occasions, which encouraged me to revise and rework. Immediately following these conferences, however, I started my post-doctoral fellowship at the University of Cambridge, which led to my moving on to new projects. The paper had been based initially on a chapter of my PhD thesis submitted to Kyoto University in 2000. Other than the translation from Japanese to English, the only other substantive change had been the accommodation of new literature. I was grateful to Masato Shikata and Kaori Katada for their encouragement during this period.

It has now been twenty years since I first tackled the topic of the paper and it is to my great surprise and pleasure to have recently discovered new readers. I would like to thank especially Dr. Mariusz Baranowski, the editor of Society Register, on whose kind invitation my work is being published here. I would also like to thank Dr. Beatrice Sasha Kobow for including the paper in the reading list for her graduate philosophy seminar at the University of Salzburg in 2020, and for inviting me there. I am grateful for her students' thoughtful questions and comments.

While I have tried in the intervening years to continually engage with the central problematics of the paper - developing a theory of an evolutionary political economy that can accommodate the issue of cultural justice, my individual works since then have not taken on the topic as a whole, but have rather developed specific points addressed in the paper. The relationship between Amartya Sen's ethical universalism and non-essential ontology on identity was explored in Yamamori 2006. The concept of need in Sen was discussed in Yamamori $(2018,2019)$, while the same concept in economics at large was explored in Yamamori $(2017,2020)$. Yamamori 2017 also tried to examine how colonialist discourse influenced the formation of the concept of need in economics, which indirectly relates to cultural justice. On Basic Income, I contrasted Nancy Fraser's work with findings from an oral history of the British working-class women's movement which had demanded Basic Income in the long 1970s (Yamamori 2014). The definitional issue of Basic Income pointed to in footnote 5 in this paper is revisited in Yamamori 2021.

When Dr. Baranowski offered me this opportunity, I thought immediately of the chance to review and incorporate all the literature to date, but soon realised what a daunting task this would be in the given time constraints. Thus the paper here is almost identical with the original in 2004, albeit in an edited new guise, for which thanks are due to Dr. Rositza Alexandrova.

Reference for acknowledgements/postscript:

Yamamori, Toru. 2006. “Universalism without essentialism: Amartya Sen and postcolonialism.” Presented at the International Conference of the Human Development and Capability Association, held at Groningen, the Netherland, 29 August - 1 September, 2006.

Yamamori, Toru. 2014. "A feminist way to unconditional basic income: claimants unions and women's liberation movements in 1970s Britain." Basic Income Studies 9(1-2): 1-24.

Yamamori, Toru. 2017. “The concept of need in Adam Smith.” Cambridge Journal of Economics 41(2): $327-47$.

Yamamori, Toru. 2018. "The concept of need in Amartya Sen: commentary to the expanded edition of Collective Choice and Social Welfare." Ethics and Social Welfare 12(4): 387-92.

Yamamori, Toru. 2019. "The Smithian ontology of 'relative poverty': revisiting the debate between Amartya Sen and Peter Townsend." Journal of Economic Methodology 26(1): 70-80.

Yamamori, Toru. 2020. "The intersubjective ontology of need in Carl Menger." Cambridge Journal of 
Economics 44(5): 1093-1113.

Yamamori, Toru. 2021. "Is a penny a month a basic income?: Revisiting the historiography of the concept of a threshold in basic income.” Presented at the Basic Income Earth Network congress, held (online) at Glasgow, UK, 18-21 August 2021.

\section{REFERENCES}

Baker, John. 1992. “An Egalitarian Case for Basic Income.” Pp. 101-127 in Arguing for Basic Income: Ethical Foundations for a Radical Reform, edited by P. Van Parijs. London: Verso.

Butler, Judith. 1990. Gender Trouble: Feminism and the Subversion of Identity. New York: Routledge.

Fraser, Nancy. 1989. Unruly Practices: Power, Discourse and Gender in Contemporary Social Theory. Minnesota: University of Minnesota Press.

Fraser, Nancy. 1997. Justice Interruptus: Critical Reflections on the Postsocialist Condition. New York: Routledge.

Gilligan, Carol. 1981. In a different voice : psychological theory and women's

Development (1986 Japanese translation, Tokyo: Kawashima Shoten.)

Habermas, Jürgen. 1981. Theorie des kommunikativen Handelns (1985-87 Japanese translation, Tokyo: Miraisha.)

Honneth, Axel. 1992. Kampf um Anerkennung: Zur Moralischen Grammatik Sozialer Konflikte. Frankfurt am Main: Suhrkamp Verlag.

Honneth, Axel. 2003. “Introduction to Japanese Version.” in Japanese translation of Honneth 1992. Tokyo: Hosei University Press.

Jordan, Bill. 1973. Paupers: The Making of the New Claiming Class. London: Routledge \& Kegan Paul.

Kelly, Paul, ed. 2002. Multiculturalism Reconsidered. Cambridge: Polity Press.

Mani, Devyani. 2002. “Culture as a Key Element of Human Security.” Nagoya: United Nations Centre for Regional Development.

Nozick, Robert. 1974. Anarchy, State, and Utopia. Basic Books.

Robeyns, Ingrid. 2000. "Hush Money or Emancipation Fee?: A Gender Analysis of Basic Income.” pp. 121-136 in Basic Income on the Agenda: Policy Objectives and Political Chances, edited by R. van der Veen \& L. Groot. Amsterdam: Amsterdam University Press.

Robeyns, Ingrid. 2001. Understanding Sen's capability approach. Cambridge: Wolfson College.

Robeyns, Ingrid. 2003. “Is Nancy Fraser's Critique of Theories of Distributive Justice Justified?" Constellations 10(4): 538-554.

Sen, Amartya. 1980. “Equality of What?” Reprinted in Sen 1982. Choice, Welfare and Measurement. Oxford: Blackwell.

Sen, Amartya. 1985. "Goals, Commitment, and Identity.” Journal of Law, Economics, and Organization 1(2): 341-355.

Sen, Amartya. 1987. The Standard of Living. Cambridge: Cambridge University Press.

Sen, Amartya. 1994. "Freedoms and Needs : An argument for the primacy of political 
rights.” The New Republic, January 10 \& 17.

Sen, Amartya. 1998. Reason before Identity. New Delhi: Oxford University Press.

Sen, Amartya. 1999. Development as Freedom. New York: Knopf.

Sen, Amartya. 2001. “Other People.” Proceedings of the British Academy 111: 319-35.

Yamamori Toru. 2000. "Redistribution and Recognition: Normative Theories and Political Economy of Welfare States.” Pp. 227-243 in Competition, Trust and Cooperation: Comparative Study, edited by Y. Shionoya \& K. Yagi. Berlin, Heidelberg: Springer.

Yamamori Toru. 2003a. "Basic Income: on a second programmatic political demand of the multitude." Revue de la Pensee d'Aujourd'hui 31(2). (the journal edited and written in Japanese).

Yamamori Toru. 2003b. “Constructive Universalism : Sen and Sensivity to Difference.” Ethique Economique 1/2003.

Taylor, Charles. 1992. “The Politics of Recognition.” Pp.25-75 in Multiculturalism and The Politics of Recognition, edited by A. Gutmann. Princeton: Princeton University Press.

Van Parijs, Philippe. 1995. Real Freedom for All: What (if Anything) can justify Capitalism? Oxford: Oxford University Press.

Van Parijs, Philippe. 2001. “A Basic Income for All.” Pp. 3-26 in What's Wrong with a Free Lunch, edited by P. Van Parijs. Boston: Beacon Press.

Woolcock, Michael, Vijayendra Rao \& Sabina Alkire. 2002. "Culture and Development economics: Theory, Evidence, Implications.” Romanian Journal of Political Science 2(2): 39-62.

\section{BIOGRAPHICAL NOTE}

Toru Yamamori is a professor at the Faculty of Economics, Doshisha University, Kyoto, Japan. He has been working at the intersection of heterodox economics, history and philosophy of economics, and oral history. His theoretical research on the concept of need in economics has been recognised with the award of the 2017 K. W. Kapp Prize from the European Association for Evolutionary Political Economy. His oral historical research on the intersectionality between women's liberation movements and claimants unions movement in the long 1970s Britain won the 2014 Basic Income Studies Best Essay prize.

OPEN ACCESS: This article is distributed under the terms of the Creative Commons Attribution Non-commercial License (CC BY-NC 4.0) which permits any non-commercial use, and reproduction in any medium, provided the original author(s) and source are credited.

ARTICLE HISTORY: Received 2021-09-01 / Accepted 2021-09-21 